\title{
An evaluation of clinical simulated encounters by pharmacy undergraduate students
}

Authors: Rick Adams ${ }^{1}$, Dr.G.Barton ${ }^{2}$, Dr.D. Bhattacharya ${ }^{1}$, Prof. R.Holland ${ }^{2}$, Prof. A.Howe ${ }^{2}$, Prof. N.Norris ${ }^{3}$, Miss C.Symms ${ }^{4}$, Prof D. Wright ${ }^{1}$

1. School of Pharmacy, University of East Anglia, 2. Norwich medical School, University of East Anglia, 3. School of Education and Lifelong Learning, University of East Anglia, 4.South Norfolk Clinical Commissioning

Background: Pharmacy students are prepared for practice through workshops, placements and OSCEs ${ }^{1}[1]$ however, simulated clinical encounters (SCE) utilising actors in realistic practice environments, may provide better preparation. The aim of this research, therefore, was to evaluate the use of SCEs in preparing students to deliver medication reviews (MR).

Method: Students, actors (patients) and assessors received written and verbal briefings prior to SCEs within a busy clinical trials unit. Students collected actors from waiting areas, undertook MR in consultation rooms and then presented the results to a real GP. Assessors, actors and the GP provided feedback on student performance. Post-completion an on-line survey, using 5 point Likert scales and free text, was used to elicit students' opinions including overall experience, location, logistics, use of actors, and feedback.

Results: 17 of 42 students surveyed responded to the survey. Figure 1 displays generally positive opinions of responding students about SCEs.

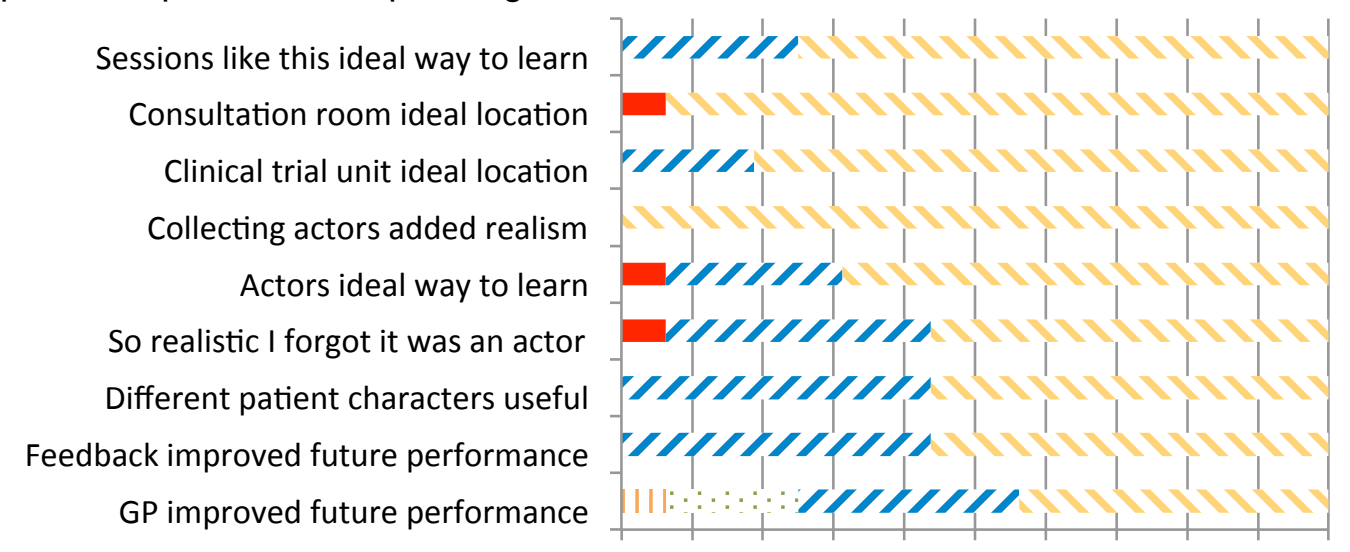

0\% 10\% 20\% 30\% 40\% 50\% 60\% 70\% 80\% 90\% 100\%

Percentage

- Fully disagree $\quad$ Disagree Unsure Agree Fully agree

Figure 1 Results of on-line student survey.

Free text comments provided additional support for realism of location and different characters in 'patient' scripts which, however, require refinement to mirror real patients. Students supported feedback provided to them. The GP's abrupt manner was reported to reduce benefit. Students reported SCEs increasing their confidence and preparing them to meet real patients for MR.

Discussion: Low survey response rate, possibly due to sending it just before final exams, limits interpretation. Responses obtained largely provide support for utilising SCEs to prepare students for MR. Specific aspects of note are the use of realism such as location, logistics, actors and their scripts but these must fully mirror real life. Students want to ensure that they receive feedback on their performance to enable further improvement. Mixed results for the GP element of the session demonstrate some benefit but needs further investigation.

\section{References}

1. Mesquita AR, Lyra Jr DP, Brito GC, et al. Developing communication skills in pharmacy:

A systematic review of the use of simulated patient methods. Patient Education and

Counseling 2010;78(2):143-48 doi: http://dx.doi.org/10.1016/j.pec.2009.07.012 